\title{
Study on Cultural Identity and Cross-cultural Communication in Teaching of International Students in China under the Context of the Belt and Road
}

\author{
Wei Zhang \\ College of Humanities \\ Tianjin Agricultural University \\ Tianjin, China
}

\begin{abstract}
Since the launch of the major initiative to jointly build the 21st century maritime silk road, universities across China have become witnesses and direct participants in the initiative. In this process, the huge differences between Chinese and foreign cultures lead to many misunderstandings and frictions. Therefore, how to effectively convey Chinese cultural values in professional teaching has become a major problem faced by many front-line teachers. In this paper, the difficulties of cross-cultural identity, language barriers and culture shock that may be encountered in the management of international students are studied from the perspective of teaching. It is hoped that the conclusions obtained here could be beneficial in solving these cross-cultural problems including cultural identity barriers and irrational reactions induced by it.
\end{abstract}

Keywords-countries along with the belt and road; cultural identity; international students; teaching

\section{INTRODUCTION}

In October 2013, during his visit to Southeast Asian countries, President of PRC Xi Jinping put forward a major initiative to jointly build the 21st century maritime Silk Road. The initiative aims to borrow the historical symbols of the ancient Silk Road, high hold the banner of peaceful development, actively develop economic cooperation partnerships with countries along the routes, and jointly build a community of shared interests, shared future and responsibility featuring political mutual trust, economic integration and cultural tolerance. Currently, The Belt and Road involve 65 countries and regions, including Mongolia in East Asia, 10 ASEAN countries, 18 west Asian countries, 8 South Asian countries, 5 central Asian countries, 7 CIS countries and 16 central and eastern European countries.

The Belt and Road initiative, as a "global perspective" that transcends countries and ideologies, is submitted by the Chinese government in response to the historical trend of ever greater interconnectedness and interdependence of human society[1].

Because of The Belt and Road initiative, China's education of overseas students has entered a new stage of development. At present, major universities across the country have become witnesses and direct participants of this initiative, as well as the ones to embody and disseminate socialist thoughts and values with Chinese characteristics.

This requires supporting reforms in teaching, management, policy making and other aspects to keep pace with The Times[2]. In the field of international education, cross-cultural communication should exert the butterfly effect, and use overseas students as a bridge in cultural diplomacy to enhance the international community's understanding of China's national conditions, policies and development path, so as to show a good national image[3].

However, there are more than 60 countries along the route of the Belt and Road. These countries have cultural differences in historical traditions, languages, social systems, religious beliefs and other aspects, which are prone to misunderstanding and friction.

How to help international students to eliminate cultural barriers and strengthen their sense of identity to Chinese culture and Chinese value orientation is a problem unavoidable in the current education of international students.

\section{OVERVIEW OF RELATED CONCEPTS}

\section{A. Cultural Identity}

The Chinese cultural dictionary interprets cultural identity as a positive cultural value judgment. That is to say, cultural groups or cultural members accept that the value and effectiveness of the new culture within the group or the different cultural factors outside the group conform to the standard of traditional cultural values.

After the identification, the new culture or cultural factors will be accepted and spread. Cultural identity is conductive to solve various problems in cross-cultural communication.

\section{B. Cross-cultural Communication}

Cross-cultural communication refers to the cross-cultural transmission of social information or the cross-cultural operation of social information system. That is to say, the flow, sharing and interaction of various cultural information in time and space. 
In essence, cross-cultural communication is a kind of cultural communication activity to communicate and foster the coexistence relationship between people in different cultures, or it is a cross-cultural and trans-regional "extension" process of social relations and social contacts.

The three elements of cross-cultural communication are cognitive elements, verbal language and non-verbal language.

Cognitive elements include cultural values, world outlook (religion) and social organization. The cultural values that most directly affect cross-cultural communication mainly involve individual, family, religion, materialism, human nature, etc.

Language is not only a form to preserve culture, but also a means to share culture. In different cultures, different languages express the same thing with different symbols and convey different meanings.

Nonverbal communication is also an element of effective communication between people from different cultures. People's body behaviors, body movements, facial expressions, concepts of time and the use of space all produce different forms of understandings based on different cultural backgrounds of the disseminators and receivers, thus delivering different information. To a large extent, it also reflects the deep structure and value system of different cultures.

Among all the factors above, cultural values are the most important factors in cross-cultural communication. Cultural differences can make cross-cultural communication extremely difficult or even impossible in some cases. Therefore, successful cross-cultural communication requires both an understanding of one's own culture and understanding of different and complementary cultures. The depth of cultural structure hinders effective cross-cultural communication. At the same time, the success of trans-cultural communication also depends on whether appropriate and affective behaviors are adopted, which do not violate established relationship principles, norms and expectations, in a specific context to achieve important goals, or obtain returns comparable to efforts and alternatives.

\section{Culture Shock}

"Culture shock" refers to a feeling of loss, confusion, rejection and even fear caused by losing all familiar social communication symbols and measures that one is familiar with when one enters an unfamiliar cultural environment. In crosscultural management, when people go abroad to work, study or settle down, they often experience different degrees of psychological reactions, which is called "culture shock". Culture shock generally goes through four stages: honeymoon period, depression (or hostility) period, recovery and adjustment period, and adaptation period.

Culture shock involves a powerful, transformative process that takes place at both the individual and societal levels. It will also exert a great impact on individual identity[4].
III. The CAuse of CROSS-CUltural IDENTITY PROBlems IN TEACHING OF INTERNATIONAL STUDENTS IN CHINA UNDER THE CONTEXT OF THE BELT AND ROAD

\section{A. Cultural Identity Barrier}

Each nation has its own national character. The cultural spirit and psychological structure together constitute the national character, which is common to a nation and formed from a certain social environment and long-term historical development[5].

The Belt and Road covers 65 countries and regions. These countries cover South Asia, West Asia, Central Europe, Northern Europe and other countries, the national characteristics and national characters of these countries are quite distinct from Chinese culture.

From the perspective of the human environment. There is a strong religious atmosphere within many countries along with the Belt and Road. In these countries religion, together with the law, governs behavior. Among these religious beliefs, the proportion of Muslims is the largest, followed by Christians, and Buddhism is the smallest. Moreover, the proportion of Buddhists is far from that of Muslims and Christians. China, by contrast, is a country made up of more diverse religious faiths, including Buddhism, Islam, Catholicism and Christianity. In addition, there are Taoism, Shamanism, Orhodox, Dongba and so on. Non-religious people also make up a large proportion. Such a different cultural atmosphere also poses cultural identity barriers for foreign students in China.

\section{B. Verbal Communication Barrier}

There are more than 65 countries and regions along the route of the Belt and Road. International students from these areas speak different first (native) languages, combined with their uneven English level. It is very difficult for them to communicate among themselves and with Chinese teachers and students. Due to communication difficulties, these international students are trapped in their own cultural circle and are unable to communicate with people in other cultural circles. As a result, they often feel lonely and been excluded, and it is difficult for them to adapt to the social, living and learning environment in China. Although, presently, many Chinese language courses are provided for international students in Chinese colleges and universities, due to students' poor Chinese ability, weak knowledge foundation, unclear learning purpose, emphasis on major learning and neglect of language learning, and the negative transfer of mother tongue in the process of second language acquisition, the growth of foreign students' Chinese ability is relatively slow. At the same time, the language barrier also aggravates the difficulty of acculturation in cross-cultural communication.

\section{Irrational Reaction Induced by Culture Shock}

Form the concept discussed above, the cultural shock is caused by the difference in the social and cultural environment, and it is caused by cultural prejudice and psychological deviation when criticizing different cultures from self-standard. After arriving in China, international students are overwhelmed by different cultures,they begin to experience each period of culture shock. The first period begins at the time when they first set foot in China. For them, everything about the new 
culture is strange and exciting. Unfortunately, the honeymoon period will not last forever; the second stage can be more difficult. After these foreign students have settled down into their new lives, they begin to feel tired and homesick. In this period, the in-adaptability to the new cultural environment leads to the irrational rejection of and withdrawal from Chinese culture. This phenomenon is especially prominent among freshmen. Under this psychological effect, they have low enthusiasm to learn Chinese and resist teachers to use Chinese in teaching. However, for international students, the delay in improving Chinese communication skills further aggravates the difficulty of learning specialized courses and integrating into Chinese culture.

\section{COUNTERMEASURES}

\section{A. To Deepen International Students' Cultural Identity for Chinese Culture Through Teaching Process}

The best way to realize the consensus of values is to dig into the common cultural memory and find the emotional resonance between China and the countries along the "The Belt and Road". Through the re-invocation of collective culture and historical memory, such as belief, totem, myth and legend, traditional custom, historical text, festival ceremony, monument and other cultural memory awakening activities, the shared historical relationship and cultural memory are reawakened.

We should learn from the experience of the United States, in the second language teaching practice in the United States, cultural concepts are required to run through the learning of cultural practices and cultural products. The teaching of English as a second language in the United States not only teaches English to learners but also subtly spreads American values and ideas. We might as well draw on such language learning standards ${ }^{[6]}$.

Reflected in the teaching activities, it requires teachers to teach the specialized theories and creatively interpret the theories with reference to actual cases of China and their home countries. Classroom discussion shall also be induced for students to make discussion and comparison by themselves. Through the discussion, foreign students could get a better understanding of specialized ideas. Furthermore, the understanding of Chinese cultural values will also be improved by looking for similarities and differences between Chinese and foreign cultures.

For example, in the teaching of Enterprise Culture, the theory of cultural differences can be introduced to enable students to learn specialized knowledge and correctly understand the causes of cultural differences. The solution to cultural conflicts is not necessary to distinguish right from wrong. At the same time, through the analysis of different cultural dimensions at home and abroad, the similarities and differences between Chinese and foreign cultures are found out to deepen students' understanding of Chinese culture.

\section{B. To Use Every Opportunity in Teaching to Motivate International Students to Practice Chinese}

The improvement of the cultural identity of a certain country will promote the foreign students' enthusiasm in language acquisition of that country. Therefore, the improvement of international students' cross-cultural identity on Chinese culture will stimulate their interest and motivation in learning Chinese, so as to encourage them to learn Chinese more actively and acquire more Chinese skills. In addition, foreign students' attitude towards Chinese also reflects their attitude towards Chinese culture. Therefore, in teaching, foreign students should be guided to accept Chinese and Chinese culture from the heart.

Reflected in the teaching activities, teachers are required to explain specialized concepts based on specific cases in China and create opportunities for international students to express their own opinions on some simple professional issues in Chinese. Additional scores shall also be designed to encourage students to answer questions in Chinese.

\section{To Use Flexible Teaching Methods to Help International Students Overcome Culture Shock}

One important way to overcome culture shock is to increase the positive contact between foreign students and Chinese students. This will help international students get more positive emotional support from Chinese cultural circle in the process of cross-cultural adaptation, which can help them better integrate into Chinese culture.

In teaching activities, teachers can arrange collaborative research tasks between Chinese and foreign students in similar courses at the same time. Specifically, the teacher can provide a topic for Chinese and foreign students to work together. This arrangement will help Chinese and foreign students to deepen their understanding of each other, and at the same time to promote the communication between international students and Chinese students, increase their mutual understanding, and expand their circle of friends. Building friendships with Chinese students helps international students build a correct understanding of Chinese culture and help them overcome the cultural shock.

In addition to the measures above, arrange some interesting classroom tasks of low difficulty for foreign students and give them positive classroom feedback can also increase students' learning confidence, improve their interest in learning, help them to overcome culture shock.

\section{CONCLUSION}

With the progress of the Belt and Road strategy and the promotion of culture going out, the number of students studying in China from countries along the route of "The Belt and Road" will increase continuously. More and more teachers are concerned about how to effectively manage foreign students and spread Chinese culture and values to them. In this paper issues about how to help foreign students to overcome language barriers, identify with Chinese culture and overcome cultural shock in the teaching process are discussed, and the following conclusions have been made:

Firstly, the teaching of specialized courses should be combined with Chinese culture and the native culture of foreign students to guide them to correctly understand Chinese culture. 
Secondly, in the teaching of specialized courses, we should actively promote students to discuss problems in Chinese and set additional scores when necessary to encourage international students to learn Chinese.

Thirdly, special classroom tasks should be designed in the teaching process to give international students more opportunities to interact with Chinese students, to expand their friends' circles and help them overcome the cultural shock.

\section{REFERENCES}

[1] Bo Feng, "Cross-cultural identity of One Belt And One Road" 12ed. Guangming Daily, 2019. (In Chinese)
[2] Yingping Liang, Yuan Liu, Jiwan Han, Xiaoyun Han, Cundong Zhao, Anyuan Zhao, "Research on cultural adaptability of foreign students from One Belt And One Road countries", vol.19. Journal of World Education, 2019, pp21-26. (In Chinese)

[3] Tiantian Wang, "Study on Chinese acquisition and Chinese cultural identity”, Vol. 22, No.1. Journal of Suzhou Education Institute, 2019, pp23-26. (In Chinese)

[4] Ioana Cupsa, “Culture Shock and Identity”, vol.2. Transactional Analysis Journal, 2018, pp181-191.

[5] Shuiyi Ding, Zhicheng Zhou, "An analysis on the management of international students in One Belt And One Road countries from a crosscultural perspective", Vol.11 No. 3. Journal of Nanyang Institute of Technology, 2019, pp80-84. (In Chinese)

[6] Li Shen, "Reflections on Chinese Cultural Education for International Students”, vol.3. Academic Exploration, 2019, pp147-151. (In Chinese) 